\title{
Peripheral Embolus
}

National Cancer Institute

\section{Source}

National Cancer Institute. Peripheral Embolus. NCI Thesaurus. Code C101249.

Acute occlusion of a peripheral blood vessel resulting from intravascular migration of material. Examples of embolic material include thrombus, fat, bone marrow, air, and amniotic fluid. (ACC) 